STANZIOLA VIEIRA, Ricardo; GOULART TAVARES, Elisa. Direito da sustentabilidade: reflexões acerca da crise ecológica marcada pela flexibilização das normas ambientais e a efetivação dos direitos humanos socioambientais. Revista Eletrônica Direito e Política, Programa de Pós-Graduação Stricto Sensu em Ciência Jurídica da UNIVALI, Itajaí, v.14, n.1, 10 quadrimestre de 2019. Disponível em: www.univali.br/direitoepolitica - ISSN 1980-7791

\title{
DIREITO DA SUSTENTABILIDADE: REFLEXÕES ACERCA DA CRISE ECOLÓGICA MARCADA PELA FLEXIBILIZAÇÃO DAS NORMAS AMBIENTAIS E A EFETIVAÇÃO DOS DIREITOS HUMANOS SOCIOAMBIENTAIS
}

\author{
SUSTAINABILITY RIGHT/ECOLOGICAL LAW: REFLECTIONS ON THE ECOLOGICAL \\ CRISIS MARKED BY THE FLEXIBILIZATION OF ENVIRONMENTAL LAW AND THE \\ EFFECTIVENESS OF SOCIO-ENVIRONMENTAL HUMAN RIGHTS
}

\author{
Ricardo Stanziola Vieira ${ }^{1}$ \\ Elisa Goulart Tavares ${ }^{2}$
}

\section{RESUMO}

Partindo-se da percepção de que a natureza é também um produto humano, o cenário de crise (degradação ecológica) originou-se com a Revolução Industrial, que de maneira desordenada culminou numa crise ambiental global a partir de um modelo de civilização que mantém uma relação insustentável com os recursos naturais existentes no Planeta Terra. Dado o enfoque ao colapso ambiental ameaçador da geração presente e futura, tem-se a necessidade de adoção de mecanismos emergenciais, para além das normas jurídicas, com o escopo prioritário de se efetivar o Estado Socioambiental de Direito contemporâneo, perspectiva de transformação da sociedade atual que altera a sua relação paradigmática com a natureza. Dessa forma, busca-se tecer algumas considerações acerca do modo como se apresenta os valores da sociedade capitalista neste contexto, em que o mito do desenvolvimento a qualquer custo reduzido a mero crescimento econômico não pode mais prosperar.

PALAVRAS-CHAVE: Meio ambiente; Direito da sustentabilidade; Efetividade.

\section{ABSTRACT}

From the perception that nature is also a human product the crisis scenario (ecological degradation) originated with the Industrial Revolution, which in a disorderly way culminated in a global environmental crisis from a model of civilization that maintains a unsustainable relationship with the natural resources on Earth. Given the focus on the threatening environmental

\footnotetext{
${ }^{1}$ Professor do Programa de Pós-Graduação em Ciência Jurídica (mestrado e doutorado) e Programa de Mestrado em Políticas Públicas - UNIVALI. Pós-doutorado pela Universidade de Limoges. Doutorado em Ciências Humanas- UFSC.

2 Mestre em Direito (Universidade de Caxias do Sul). Docente permanente da Escola Superior de Advocacia da OAB - Seção SP. Docente e pesquisadora nos cursos de graduação e pós graduação em Direito (FUCAP), Membro do Grupo de Pesquisa Metamorfose Jurídica - CNPq. Especialista em Direito Civil e Empresarial. Advogada.
} 
STANZIOLA VIEIRA, Ricardo; GOULART TAVARES, Elisa. Direito da sustentabilidade: reflexões acerca da crise ecológica marcada pela flexibilização das normas ambientais e a efetivação dos direitos humanos socioambientais. Revista Eletrônica Direito e Política, Programa de Pós-Graduação Stricto Sensu em Ciência Jurídica da UNIVALI, Itajaí, v.14, n.1, $1^{\circ}$ quadrimestre de 2019. Disponível em: www.univali.br/direitoepolitica - ISSN 1980-7791

collapse of the present and future generation, there is a need to adopt emergency mechanisms, in addition to legal norms, with the priority scope of implementing the Socio-environmental State of contemporary law, perspective of transformation of the current society which changes its paradigmatic relationship with nature. In this way, we try to make some considerations about how the values of capitalist society are presented in this context, in which the myth of development at any cost reduced to mere economic growth can no longer prosper.

KEYWORD: Environment, Right of sustainability, Effectiveness

\section{INTRODUÇÃO}

A natureza é fornecedora de bens e provedora de serviços ao homem, como a regulação da composição atmosférica, ciclagem de nutrientes, conservação dos solos, qualidade de água, fotossíntese, decomposição dos resíduos, dentre outros, os quais proporcionam condições para a manutenção de sua espécie, neste prisma, é razoável entender que, apesar destes serviços não possuírem preço, não deixam de ser extremamente valiosos e caros à sociedade ${ }^{3}$.

A responsabilidade para com o outro nos faz humanos, ao passo que a responsabilidade para com a política nos faz cidadãos. Os inúmeros desdobramentos temáticos visam (re)construir um Estado de Direito Ambiental que não permite uma exposição exaustiva do tema. Com a concretização do Estado de Direito Ambiental busca-se reconhecer sua importância inquestionável no sentido de avanço na tutela das bases fundamentais da vida, traduzido nos direitos humanos.

Dentro da ótica do Direito, faz-se necessário, primordialmente, buscar uma reflexão sobre o papel da norma no mundo real e não sobre a estrutura normativa propriamente dita. O direito é fruto de determinada cultura, que se vale também dos mais vastos campos dos saberes, como a sociologia, da filosofia, da história,

3BESUSAN, 2002 apud ALTMANN, Alexandre. O desenvolvimento sustentável e os serviços ambientais. In: RECH, Adir Ubaldo; ALTMANN, Alexandre (Org.). Pagamento por Serviços Ambientais. Imperativos jurídicos e ecológicos para a preservação e a restauração das matas ciliares. Caxias do Sul: EDUCS, 2009. p. 81. 
STANZIOLA VIEIRA, Ricardo; GOULART TAVARES, Elisa. Direito da sustentabilidade: reflexões acerca da crise ecológica marcada pela flexibilização das normas ambientais e a efetivação dos direitos humanos socioambientais. Revista Eletrônica Direito e Política, Programa de Pós-Graduação Stricto Sensu em Ciência Jurídica da UNIVALI, Itajaí, v.14, n.1, $1^{\circ}$ quadrimestre de 2019. Disponível em: www.univali.br/direitoepolitica - ISSN 1980-7791

da economia e da política, sem reduzir-se um ao outro. Sem negar a dogmática intrínseca do Direito, indispensável na sua interpretação, o desafio é fazer com que seu papel natural seja não apenas de estabelecer uma ordem jurídica positivada mas principalmente esclarecer um conteúdo eficiente e palpável, não restrito ao texto jurídico abstrato.

Uma vez conscientes da opção maioria dos Estados, inclusive do Brasil pelo desenvolvimentismo e consequentemente pelo difícil acesso à informação, participação e controle social cidadão em temas socioambientais, temos as consequências certas deste processo.

Atualmente o que se vê são situações de conflitos socioambientais e injustiça ambiental em que o papel de Direito é de suma importância. De mais a mais, vem ocorrendo de forma difusa em decorrência de fenômenos, de um lado, como aumento da pobreza e das desigualdades econômico-sociais e consequente vulnerabilidade, e de outro lado pelas alterações climáticas, naturais ou causadas pelo homem (aumento de eventos extremos, desastres naturais) e o avanço do modelo desenvolvimentista.

Destaque para temas como desastres ambientais (e seus atingidos mais frequentes), violação dos direitos socioambientais de grupos vulneráveis como as crianças e adolescentes, modelo de desenvolvimento do agronegócio (muitas vezes caracterizado pelo forte êxodo rural de pequenos produtores ou quando não, pela sua submissão sistemática ao que se denomina, pomposamente, de "contratos de integração" e por fim a dramática situação do reconhecimento de territórios das populações e comunidades tradicionais ${ }^{4}$.

\footnotetext{
${ }^{4}$ Se por um lado a agenda da Reforma Agrária vem aos poucos desaparecendo do horizonte do governo, a questão indígena sequer entrou na agenda da esquerda brasileira no poder. "Retrocedemos muito neste período. Se antes lutávamos pelo cumprimento dos nossos direitos, hoje lutamos para não perder esses direitos reconhecidos na Constituição", lamenta Sônia Guajajara, coordenadora da Coordenação das Organizações Indígenas da Amazônia Brasileira (Coiab). Em média, os governos dos presidentes Lula e Dilma homologaram menos terras, em número e extensão, do que os antecessores José Sarney, Fernando Collor de Melo, Itamar Franco e Fernando Henrique Cardoso, destaca reportagem do Brasil de Fato. Na avaliação dos defensores dos direitos indígenas, a razão para este retrocesso está na opção de modelo desenvolvimentista para o campo e para as florestas adotado pelos governos nesta última década. "Pela origem do governo ligado aos movimentos sociais, o movimento indígena criou muita expectativa, mas ele fez uma aliança com os latifundiários e as mineradoras, deixando os nossos interesses de lado", lembra Rildo Kaingang,
} 
STANZIOLA VIEIRA, Ricardo; GOULART TAVARES, Elisa. Direito da sustentabilidade: reflexões acerca da crise ecológica marcada pela flexibilização das normas ambientais e a efetivação dos direitos humanos socioambientais. Revista Eletrônica Direito e Política, Programa de Pós-Graduação Stricto Sensu em Ciência Jurídica da UNIVALI, Itajaí, v.14, n.1, 10 quadrimestre de 2019. Disponível em: www.univali.br/direitoepolitica - ISSN 1980-7791

De outro norte, a questão territorial merece destaque no cenário de injustiça ambiental decorrente direta ou indiretamente do modelo desenvolvimentista. Sem pretensão de enunciar todos os casos conhecidos ${ }^{5}$ ou de aprofundá-los mencionamos alguns que tem chamado a atenção no Brasil dos últimos tempos: o caso dos povos indígenas (caso de Belo Monté, Aldeia Maracanã, Kaiowaa Guarani, Ticuna, entre outros)7; territórios quilombolas (o exemplo de Alcântara MA é um dos mais citados por apresentar às claras a postura do Estado Brasileiro); caso das caiçaras e pescadores artesanais (como nos enfrentamentos de grandes grupos transnacionais - em parceria com o Estado - como no caso de CSA e Thyssenkrupp Sepetiba/RJ e do complexo petroquímico do Rio de Janeiro (COMPERJ), na Baia da Guanabara, grandes obras de infraestrutura como os portos de Pecém/CE, Suape/PE entre tantos outros grandes projetos quase "inquestionáveis" do Plano de Aceleração do Crescimento - PAC) ${ }^{8}$.

coordenador da Articulação dos Povos Indígenas do Brasil. (Cenários para 2013. Povos indígenas, 'entraves' ao modelo de desenvolvimento. Publicado em 24 janeiro de 2017. Disponível em: <http://goo.gl/SNquTq>. Acesso em 14 de Fevereiro de 2017.

5 Algumas referências neste sentido são o site da Rede Brasileira de Justiça ambiental, www.justicaambiental.org.br, o Blog "Combate ao Racismo ambiental" http://racismoambiental.net.br/, e o "Mapa de conflitos envolvendo a justiça ambiental e saúde no Brasil - http://www.conflitoambiental.icict.fiocruz.br/.

6 A construção da Hidrelétrica de Belo Monte, na barragem do Rio Xingu, no Pará, também é emblemático nessa questão. Considerada a maior obra do Programa de Aceleração do Crescimento (PAC), do governo federal, a construção além de ter sérios impactos ambientais (ver na matéria publicada no site da EPSJV), deve deslocar 14 diferentes povos indígenas, totalizando milhares de famílias, de suas terras originárias. O estudo de viabilidade técnica vem sendo executado desde 1980, mas foi em 2009, momento em que foi apresentado o novo Estudo de Impacto Ambiental (EIA) e logo após, no início de 2010, quando o Ministério de Meio Ambiente concedeu a licença ambiental prévia para sua construção, que os conflitos ficaram mais tensos. Até agora grande parte das condicionantes propostas no estudo não foram cumpridas, no entanto, o projeto está sendo realizado em meio a grandes entraves e tensões.

7 Trata-se do espaço do antigo Museu do Índio, no Rio de Janeiro. Instalado em um antigo casarão de 1862, o local abrigava a chamada "Aldeia Maracanã", na qual conviviam índios de diversas etnias como Puris, Botocudos, Tapajós, Guajajara, pataxós, tukanos, fulni-o e apurinãs, Potiguaras, Guarani, Kaingáng, Krikati, Pankararu, Xavante, Ashaninkas, entre outras. O espaço fica nas proximidades do Estádio Mário Filho, o Maracanã - que esteve em reforma desde 2010 por conta das exigências da Federação Internacional de Futebol (Fifa) para abrigar jogos da Copa do Mundo, realizada em 2014.

8 Cite-se a entrevista com Alexandre Anderson da ONG AHOMAR concedida à EPSJV: "Os pescadores artesanais, que trazem sua cultura de várias gerações e têm o cordão umbilical diretamente ligado com os ecossistemas também estão sofrendo violações de direitos humanos. Eles estão sendo expulsos dos seus territórios porque as baias estão perdendo a finalidade de ecossistemas e de bens comuns. Dentre as suas reivindicações está o reconhecimento dessas comunidades como 
STANZIOLA VIEIRA, Ricardo; GOULART TAVARES, Elisa. Direito da sustentabilidade: reflexões acerca da crise ecológica marcada pela flexibilização das normas ambientais e a efetivação dos direitos humanos socioambientais. Revista Eletrônica Direito e Política, Programa de Pós-Graduação Stricto Sensu em Ciência Jurídica da UNIVALI, Itajaí, v.14, n.1, $1^{\circ}$ quadrimestre de 2019. Disponível em: www.univali.br/direitoepolitica - ISSN 1980-7791

\section{ENTRE A OPERATIVIDADE DO DIREITO E O DESENVOLVIMENTO SUSTENTÁVEL: O BRASIL NO CONTEXTO DA SOCIEDADE DE RISCO}

\subsection{Estado De Direito Do Ambiente: Uma Mudança De Paradigma}

Com base no exposto introdutório, subentende-se uma ordem jurídica é legítima, na forma de como ela igualmente assegura aos cidadãos as bases da autonomia da ação pública e privada. Especialmente no caso das normas constitucionais, somente o texto normativo é abstrato. Ou seja, o caráter da norma é definido quando se sua aplicação. A concretização da norma, portanto, compreende tanto sua interpretação e aplicação, como, a solução de um caso jurídico.

Contudo, não se pode dissociar, sobretudo na norma constitucional, a interpretação do direito da posição política. Pode-se dizer que a concretização do direito é uma das formas de manifestação da política e que está intimamente senão diretamente -, ligada a comunicação recíproca de intepretação do texto legal. Assim, a norma jurídica constitucional não é mera positivação de conteúdo imperativo hipotético e prescrito, pois é na norma jurídica constitucional que se extrai o instrumento mediador das atividades sociais como meio para o alcance de finalidades coletivas como um todo.

Partindo-se da problemática da sociedade mundial do risco, contornada pela histórica degradação da natureza e multiplicação desordenada e anônima de danos invisíveis e desconhecidos pelos seus membros, manifesta-se a necessidade de

\footnotetext{
tradicionais, o direito à pesca e aos seus territórios, a exemplo do Movimento Pescadores e Pescadoras artesanais (MPP)". Jô Brandão, secretária especial sobre populações e comunidades tradicionais (Governo Federal) explica que desde o Decreto 6040/07 as comunidades caiçaras e os pescadores artesanais já são consideradas comunidades tradicionais e também têm representantes na Comissão Nacional de Desenvolvimento Sustentável dos Povos e Comunidades Tradicionais (CNPCT), que atua com apoio do Ministério do Desenvolvimento Social no fortalecimento social, econômico, cultural e ambiental dos povos e comunidades tradicionais. "O caso dos caiçaras que vivem de pesca artesanal ainda é mais complicado porque esbarra também na questão ambiental, como é vivido pela comunidade da região da Jureia, em São Paulo, que se encontram agora em uma área de preservação ambiental. Dependendo do formato e do modelo desta área de preservação, ela não permite a presença das pessoas no local, que é o caso de lá, e isso tem gerado muito conflito porque os caiçaras estão ficando desamparados", lembra. Disponível em: <http://goo.gl/QsklLE> . Acesso em: 07 de outubro de 2016.
} 
STANZIOLA VIEIRA, Ricardo; GOULART TAVARES, Elisa. Direito da sustentabilidade: reflexões acerca da crise ecológica marcada pela flexibilização das normas ambientais e a efetivação dos direitos humanos socioambientais. Revista Eletrônica Direito e Política, Programa de Pós-Graduação Stricto Sensu em Ciência Jurídica da UNIVALI, Itajaí, v.14, n.1, $1^{\circ}$ quadrimestre de 2019. Disponível em: www.univali.br/direitoepolitica - ISSN 1980-7791

um Estado capaz de enfrentar a complexidade destes desafios, dependendo, nesta lógica, de mudança nos padrões e tomada de decisões humanas. ${ }^{9}$

No painel da sociedade moderna destaca-se o surgimento do Direito Ambiental estritamente vinculado às dificuldades do Estado e dos cidadãos de enfrentar uma complexa situação inserida no seio da sociedade industrial: a degradação ambiental. A possível "neutralização" ou caminhada a uma maior segurança social face à iminência dos riscos atualmente vividos conduz à busca de um novo modelo de Estado, no qual se sobreponha o dever jurídico-estatal de respeito e proteção da dignidade humana em conjunto com a exigência de uma medida mínima de amparo ambiental.

Exatamente neste ponto, torna-se imprescindível o esforço à consecução de um Estado de Direito Ambiental hábil a proteger adequadamente o meio ambiente, a estimular a consciência ambiental inerente ao exercício da responsabilidade compartilhada e à participação pública, e a favorecer a jurisdicionalização de ferramentas capazes de garantir um nível de proteção apropriado aos bens públicos ambientais e toda coletividade que os usufrui.

Na configuração do Estado de Direito Ambiental a questão da segurança ambiental toma papel central, em que o Estado assume a função de resguardar os cidadãos contra novas formas de violação da sua dignidade e dos seus direitos fundamentais por força dos impactos ambientais produzidos pela sociedade de risco.

O desenho da tutela ambiental nos ordenamentos jurídicos globais iniciou-se, propriamente, após o encontro mundial de Estocolmo de 1972, quando as Constituições passaram a gravitar em outro eixo de legitimidade, no dos direitos sociais e dos vastos interesses corporativos que neles se enraízam ${ }^{10}$. Importante ressaltar que a construção do Estado de Direito Ambiental se fortalece quando a

\footnotetext{
9"Natureza", no contexto da sociedade pós-moderna, é um conceito, norma, recordação, utopia, ou mesmo um plano alternativo. Tudo isso porque o estado global de fusão contraditória de natureza e sociedade em uma relação de vícios mútuos somada em todos os tempos, implicou num estado da natureza hoje que distancia a cada dia a noção do que seja ela propriamente. BECK, Ulrich. La sociedad del riesgo global. Tradução de Jesús Alborés Reys. Madrid: Siglo vientiuno, 2002. p. 32.
}

${ }^{10}$ BONAVIDES, Paulo. A constituição aberta. Temas políticos e constitucionais da atualidade com ênfase no Federalismo das Regiões. 3. ed. São Paulo: Malheiros, 2004. p. 195. 
STANZIOLA VIEIRA, Ricardo; GOULART TAVARES, Elisa. Direito da sustentabilidade: reflexões acerca da crise ecológica marcada pela flexibilização das normas ambientais e a efetivação dos direitos humanos socioambientais. Revista Eletrônica Direito e Política, Programa de Pós-Graduação Stricto Sensu em Ciência Jurídica da UNIVALI, Itajaí, v.14, n.1, $1^{\circ}$ quadrimestre de 2019. Disponível em: www.univali.br/direitoepolitica - ISSN 1980-7791

tutela do meio ambiente é versada no texto constitucional, todavia, não se pode acreditar que tão somente o postulado normativo constitucional poderá, de fato, alterar as condições de vida com que a sociedade tem desenvolvido há séculos.

Nesse espeque, é dever do Estado garantir instrumentos para viabilizar a consagração dos princípios democráticos, comprometido com a realização do bemestar da sociedade. Processos adequados de deliberação possibilitam acordos que satisfaçam a racionalidade (enquanto defesa dos direitos liberais) e a legitimidade democrática (baseada na soberania popular) ${ }^{11}$.

Essa ideia de Estado de Direito do Ambiente, utópica ou não, não deixa de ser uma tentativa de contenção dos problemas advindos da sociedade risco, pois é também uma de suas metas, o gerenciamento de riscos ambientais com a atração de novas formas e reconhecimento de direitos até tão esquecidos e ignorados pelas anteriores formas de Estado Liberal e Social.

O direito ao meio ambiente ecologicamente equilibrado nada mais é do que um direito fundamental, porque é uma prerrogativa individual prevista no texto constitucional condicionada à realização de uma série de ações de natureza público-privadas, capazes de garantir condições mínimas de desenvolvimento das potencialidades individuais, bem como de uma ordem social livre e digna.

A mudança de paradigma no âmbito estatal do Estado Liberal ao Estado Socioambiental requer rupturas drásticas em sua estrutura organizacional, iniciando-se com a harmonização entre desenvolvimento econômico e meio ambiente e na reavaliação dos atuais instrumentos da política ambiental, com a finalidade de se inquirir novos mecanismos de políticas públicas ambientais capazes de oferecer modificações significativas e de aplicabilidade imediata.

\footnotetext{
11 Nessa mesma linha, Canotilho acrescenta que o conteúdo dos direitos fundamentais é decisivamente constitutivo das estruturas básicas do Estado e da sociedade. CANOTILHO, José Joaquim Gomes. Direito constitucional e teoria da constituição. 2. ed. Coimbra: Almedina, 1998. p. 499.
} 
STANZIOLA VIEIRA, Ricardo; GOULART TAVARES, Elisa. Direito da sustentabilidade: reflexões acerca da crise ecológica marcada pela flexibilização das normas ambientais e a efetivação dos direitos humanos socioambientais. Revista Eletrônica Direito e Política, Programa de Pós-Graduação Stricto Sensu em Ciência Jurídica da UNIVALI, Itajaí, v.14, n.1, $1^{\circ}$ quadrimestre de 2019. Disponível em: www.univali.br/direitoepolitica - ISSN 1980-7791

Noutro ponto, é patente a vasta necessidade de mudança de atuação dos tribunais pátrios na perspectiva de encaminharem melhores condições de operatividade do direito na concretização da proteção ambiental ${ }^{12}$, bem como de uma alteração significativa na postura dos órgãos públicos, em geral, no sentido de aliar políticas públicas e planos econômicos com os princípios jurídico-constitucionais.

Indispensável, portanto, a amplitude e intensificação dos mecanismos de participação popular capazes de enrijecer a democracia participativa dos conselhos ou mesmo do acesso à informação pelo cidadão, fatores que certamente contribuirão não apenas à responsabilidade compartilhada ${ }^{13}$ no controle da degradação ambiental, mas, sobretudo, na consciência acerca da consequência destes.

Além da imprescindibilidade de normas jurídicas aptas a salvaguardar a tutela do meio ambiente e preveni-lo das variadas formas de deturpação, acima de tudo, faz-se relevante a garantia de proteção efetiva deste direito fundamental ${ }^{14}$. Oportunamente, o Estado brasileiro, através da sua Constituição Federal de 1988, convocou o Poder Público e a comunidade para o dever de preservação, sendo estes parceiros do pacto democrático, no escopo de se chegar à sustentabilidade ecológica ${ }^{15}$.

Indispensável, portanto, a amplitude e intensificação dos mecanismos de participação popular capazes de enrijecer a democracia participativa dos conselhos ou mesmo do acesso à informação pelo cidadão, fatores que certamente contribuirão não apenas à responsabilidade compartilhada ${ }^{16}$ no controle da degradação ambiental, mas, sobretudo, na consciência acerca da consequência destes.

\footnotetext{
${ }^{12}$ LEITE, José Rubens; AYALA, Patryck de Araújo. Direito ambiental na sociedade de risco. 2. ed. Rio de Janeiro: Forense Universitária, 2004.p. 349.

${ }^{13}$ Termo recorrentemente utilizado por Morato Leite. Cf. LEITE; AYALA, 2004. p. 157.

${ }^{14}$ Norberto Bobbio disserta que os direitos do homem, sempre novos e cada vez mais extensos, apesar de terem sempre argumentos convincentes, precisam, sobretudo, de garantia de uma proteção efetiva. BOBBIO, Norberto. A Era dos Direitos. Rio de Janeiro: Elsevier, 2004. p. 80.

${ }^{15}$ BENJAMIN, 2010. p. 133.

${ }^{16}$ Termo recorrentemente utilizado por Morato Leite. Cf. LEITE; AYALA, 2004. p. 157.
} 
STANZIOLA VIEIRA, Ricardo; GOULART TAVARES, Elisa. Direito da sustentabilidade: reflexões acerca da crise ecológica marcada pela flexibilização das normas ambientais e a efetivação dos direitos humanos socioambientais. Revista Eletrônica Direito e Política, Programa de Pós-Graduação Stricto Sensu em Ciência Jurídica da UNIVALI, Itajaí, v.14, n.1, $1^{\circ}$ quadrimestre de 2019. Disponível em: www.univali.br/direitoepolitica - ISSN 1980-7791

\subsection{Estado Brasileiro: O Modelo Econômico Vigente E Os Limites Do Crescimento}

\subsubsection{Desenvolvimento: Algumas Abordagens}

A sociedade de risco difundida pelo sociólogo alemão Ulrich Beck está contextualizada essencialmente na modernidade, nos traços do desenvolvimento tecnológico, da produção e consumo excessivos, na cadeia mundial dos alimentos e produtos, no livre mercado econômico, na globalização mercadológica, política, cultural e social, e no intensivo modelo de produção degradador dos recursos naturais.

O avassalador capitalismo da era moderna trouxe consigo significativo reforço à exploração ambiental em razão do crescimento populacional ser diretamente proporcional ao aumento da ocupação, consumo e geração de resíduos, construindo-se um ciclo habitualmente desprovido de sustentabilidade.

O atual modelo-dominante é a mercantilização e a submissão de quase todas as transações, mesmo aquelas relacionadas à produção de conhecimento à lógica do lucro, dos custos e dos benefícios. ${ }^{17} \mathrm{Na}$ ótica do modelo econômico desenvolvimentista - que deu o tom às políticas de expansão econômica do pósguerra -, a superação da pobreza extrema, da fome e da marginalização social das maiorias viria naturalmente como resultado dos investimentos em grandes obras de infraestrutura, tais como rodovias, hidrelétricas e projetos de irrigação. Salvaguardas ambientais eram vistas como entraves ao progresso, concebido como resultado de taxas elevadas de crescimento do Produto Interno Bruto (PIB).

As instabilidades da sociedade moderna atormentam cada vez nossas vidas geram desconfianças quanto à alusão de um progresso histórico contínuo na direção de algo mais razoável e melhor. Sob a ótica da sociedade contemporânea, facetada pela iminência de incertezas de diversas tipologias e graus, decorrentes de fatos e

17 Cf. HARVEY, David. Espacios de esperanza. Madrid: Akal, 2003, p. 255. 
STANZIOLA VIEIRA, Ricardo; GOULART TAVARES, Elisa. Direito da sustentabilidade: reflexões acerca da crise ecológica marcada pela flexibilização das normas ambientais e a efetivação dos direitos humanos socioambientais. Revista Eletrônica Direito e Política, Programa de Pós-Graduação Stricto Sensu em Ciência Jurídica da UNIVALI, Itajaí, v.14, n.1, $1^{\circ}$ quadrimestre de 2019. Disponível em: www.univali.br/direitoepolitica - ISSN 1980-7791

decisões históricas globais, exsurgem dificuldades relacionadas à provisão de um meio ambiente qualificado à idade presente e futura.

No Brasil, em vez de serem privilegiadas a distribuição de renda, uma economia mais autônoma e a proteção ambiental, o que vingou foram os incentivos públicos - que levaram ao desmatamento do Cerrado, da Mata Atlântica e da Amazônia e a instalação do parque automobilístico em detrimento das ferrovias. Importava remover obstáculos naturais para o progresso avançar, como foi o caso da chamada Revolução Verde, iniciada na década de 1940. A expressão, cunhada em 1966, refere-se a um programa para aumentar a produção agrícola no mundo e assim acabar com a fome, por meio de sementes geneticamente melhoradas, uso de agrotóxicos, fertilizantes e maquinário ${ }^{18}$.

Nesse sentido, os limites do crescimento, a ultrapassagem dos limites e a crise ambiental são as maiores contradições do atual modelo. ${ }^{19}$ Além do agravamento dos problemas sociais e da herança econômica - hiperinflação, elevado endividamento externo e arrocho salarial, as políticas convencionais de desenvolvimento afetaram profundamente o meio ambiente. Tornaram-se corriqueiros os desastres ecológicos, por conta de acidentes químicos e derramamento de petróleo; a poluição do ar e dos recursos hídricos; o desmatamento; a devastação de mangues e as áreas úmidas; a contaminação por agrotóxicos e outras substâncias e uma montanha de lixo que se esparrama por cidades, mares, rios e lagos.

\footnotetext{
18 No Brasil, além da expansão do agronegócio em regiões antes não intensamente ocupadas pelo ser humano, houve rápida urbanização, e em consequência da falta de preocupação com o bemestar das pessoas, ampliaram-se favelas e moradias insalubres e cresceu a poluição ambiental (também resultante do déficit em saneamento). Por outro lado, demandas por mais "desenvolvimento", sobretudo no setor industrial, para ofertar empregos à população urbana, passaram a povoar o imaginário de progresso de pequenas, médias e grandes cidades brasileiras.

19 Cf. GARCÍA, E.; RODRIGUÉZ, J. M. La expansión de la civilización industrial y sus limites. In: GARCÍA, Ferrando Manuel. (Coord.). Pensar nuestra sociedade global: fundamentos de Sociologia. Valencia: Tirant lo Blanch, 2005. p. 266-268.
} 
STANZIOLA VIEIRA, Ricardo; GOULART TAVARES, Elisa. Direito da sustentabilidade: reflexões acerca da crise ecológica marcada pela flexibilização das normas ambientais e a efetivação dos direitos humanos socioambientais. Revista Eletrônica Direito e Política, Programa de Pós-Graduação Stricto Sensu em Ciência Jurídica da UNIVALI, Itajaí, v.14, n.1, $1^{\circ}$ quadrimestre de 2019. Disponível em: www.univali.br/direitoepolitica - ISSN 1980-7791

Apesar da prevalência do desenvolvimentismo, ambientalistas, movimentos sociais e cientistas que pesquisavam os efeitos do modelo de produção e consumo vigentes na saúde humana e no meio ambiente, gradualmente aumentavam sua influência sobre a opinião pública.

Uma crítica interessante que tem sido feita ao "desenvolvimentismo" e ao "consumerismo" de nossos dias provém de diversos trabalhos acadêmicos, ou não, como o estudo do Clube de Roma - Limites ao crescimento -, e mais recentemente a revisão de indicadores sobre capacidade de suporte dos ecossistemas planetários. Um autor de destaque na atualidade é o sociólogo francês Serge Latouche. Este pesquisador apresenta a tese provocadora: "Um certo modelo de sociedade de consumo acabou. Agora, o único caminho para a abundância é a frugalidade, pois permite satisfazer todas as necessidades sem criar pobreza e infelicidade". ${ }^{20}$

Entenda-se que o "decrescimento" aqui não significa apologia à recessão. Ao contrário, visa justamente questionar as bases do atual modelo de "crescimento" que agride tanto o equilíbrio ecossistêmico, os bens difusos, como também a qualidade de vida e saúde da população.

Em breve análise, a lei da entropia aparece como "lei limite" em face do processo econômico desenfreado, segundo ${ }^{21}$

A lei da entropia é filha da racionalidade econômica e tecnologia, do imperativo de se maximizar a produtividade e minimizar a perda de energia. Em sua procura de ordem, controle e eficiência, essa racionalidade desencadeou as sinergias negativas que haveriam de levar à degradação da natureza. Nesse sentido, a escassez como princípio que fundamenta a ciência econômica troca de sinal e adquire um novo significado. O problema do esgotamento dos recursos naturais (renováveis ou não) nem dos limites da tecnologia para extraí-los e transformá-los; nem sequer dos crescentes custos de geração de recursos energéticos. Os limites do crescimento econômico são estabelecidos pela lei-limite da

\footnotetext{
20 Serge Latouche é professor emérito de ciências econômicas da Universidade de Paris-Sud, universalmente

conhecido como o "profeta do decrescimento feliz ou da toeria do decrescimento".

21 LEFF, Henrique. Racionalidade Ambiental a Reapropriação Social da Natureza. São Paulo: Civilizacao Brasileira, 2006, p. 175-176.
} 
STANZIOLA VIEIRA, Ricardo; GOULART TAVARES, Elisa. Direito da sustentabilidade: reflexões acerca da crise ecológica marcada pela flexibilização das normas ambientais e a efetivação dos direitos humanos socioambientais. Revista Eletrônica Direito e Política, Programa de Pós-Graduação Stricto Sensu em Ciência Jurídica da UNIVALI, Itajaí, v.14, n.1, $1^{\circ}$ quadrimestre de 2019. Disponível em: www.univali.br/direitoepolitica - ISSN 1980-7791

entropia, que rege os fenômenos da natureza e conduz o processo irreversível e inelutável da degradação da matéria e da energia no universo.

Conclui-se dessa forma que a constante busca por uma economia do lucro e descarte está diretamente relacionada com a baixa entropia de seu ambiente, como um fluxo incessante de entropia rumo a fim instransponível 22.

\section{JUSTIÇA AMBIENTAL: A DUPLA FUNCIONALIDADE DA PROTEÇÃO AMBIENTAL NO ORDENAMENTO JURÍDICO BRASILEIRO E A (IN)EFICÁCIA DAS NORMAS VIGENTES FRENTE À POBREZA}

A consagração do ambiente como um bem comum a todos, estabelece, para o Estado adotar condutas positivas ou negativas buscando potencializar ao máximo a proteção ambiental no âmbito das funções e dos entes estatais. Dessa forma, "o atual projeto normativo-constitucional do Estado (socioambiental) de Direito brasileiro, delineado pela Lei Fundamental de 1988, conforma um Estado 'guardião e amigo' dos direitos fundamentais" ${ }^{23}$, de forma que todos os poderes e órgãos se encontram vinculados às diretrizes ecológicas constitucionais. As normais ambientais, por seu turno, são voltadas essencialmente a uma relação social e não apenas a proteção do ecossistema. Em outras palavras, significa dizer que tais normas de proteção ao meio ambiente são reflexos de uma constatação social paradoxal.

Dentre as características de um bem ambiental destaca-se a sua intangibilidade, o que significa dizer que assim é tido uma vez que seu conteúdo está inacessível às tentativas de descarterirazação, atingindo um patamar superior de proteção, estando imune `outras normas.

22 Para melhor elucidar a lei de entropia ver GEORGESCU-ROEGEN, Nichola. O decrescimento: entropia, ecologia, economia. Tradução de Maria José Perillo Isaac. São Paulo: Senac, 2012, p. 63.

${ }^{23}$ SARLET, Ingo Wolfang; FENSTERSEIFER, Tiago. Direito constitucional ambiental. São Paulo: Revista dos Tribunais, 2011. p. 192. 
STANZIOLA VIEIRA, Ricardo; GOULART TAVARES, Elisa. Direito da sustentabilidade: reflexões acerca da crise ecológica marcada pela flexibilização das normas ambientais e a efetivação dos direitos humanos socioambientais. Revista Eletrônica Direito e Política, Programa de Pós-Graduação Stricto Sensu em Ciência Jurídica da UNIVALI, Itajaí, v.14, n.1, $1^{\circ}$ quadrimestre de 2019. Disponível em: www.univali.br/direitoepolitica - ISSN 1980-7791

A partir da percepção de que o agravamento dos problemas ambientais que solapam a humanidade em escala global está, em muito, atrelado à resistência e dificuldade de implementação de uma dita justiça ambiental (governança) pelos distintos governos, o socioambientalismo e o conceito de justiça ambiental apresentam-se como novas concepções na abordagem da questão ambiental, que visam à conjugação dos fatores estritamente ambientais e de caráter técnico com o seu contexto social, econômico, cultural, étnico e político. Reconhecem os saberes, os fazeres populares, as suas construções culturais sobre o seu ambiente como fatores determinantes no trato jurídico dos conflitos incidentes sobre bens socioambientais e como fontes de renovação do Direito Ambiental rumo a um "Direito da Sustentabilidade". Como bem coloca Santilli24, "o novo paradigma de desenvolvimento preconizado pelo socioambientalismo deve promover e valorizar a diversidade cultural e a consolidação do processo democrático no país, com ampla participação social na gestão ambiental".

A concepção de Justiça Ambiental, desenvolvida pelo movimento internacional Environmental Justice, tem como foco central a distribuição equitativa de riscos, custos e benefícios ambientais, independentemente de fatores não justificáveis racionalmente, tais como etnia, renda, posição social e poder; o igual acesso aos recursos ambientais e aos processos decisórios de caráter ambiental, traduzindose em sua democratização. Para tanto, faz-se necessária a criação de condições estruturais favoráveis à organização e ao empoderamento da sociedade como sujeitos ativos do processo de gestão ambiental. Parte da constatação de que grupos fragilizados em sua condição socioeconômica, étnica e informacional, que afetam a sua aptidão para o exercício da cidadania, arcam com uma parcela desproporcional de custos ambientais e enfrentam maiores dificuldades de participação nos processos decisórios ambientais ${ }^{25}$.

\footnotetext{
${ }^{24}$ SANTILLI, Juliana. Socioambientalismo e novos direitos - proteção jurídica à diversidade biológica e cultural. São Paulo: Peirópolis, 2004, p. 34.

$25 \mathrm{O}$ termo justiça ambiental, entendido como reação à planejada desigualdade na distribuição de custos e benefícios do no decorrer do processo de crescimento/ desenvolvimento, surge nas décadas de 70/80 a partir de ações do movimento negro (especialmente nos EUA e África Sul), que percebeu as novas formas de violência e discriminação, agora através do cenário ambiental, de que vinham sendo vítimas. A partir deste momento nasce o conceito de "racismo ambiental" e posteriormente de "justiça ambiental" uma vez que tais discriminações e violências decorrentes do modelo de
} 
STANZIOLA VIEIRA, Ricardo; GOULART TAVARES, Elisa. Direito da sustentabilidade: reflexões acerca da crise ecológica marcada pela flexibilização das normas ambientais e a efetivação dos direitos humanos socioambientais. Revista Eletrônica Direito e Política, Programa de Pós-Graduação Stricto Sensu em Ciência Jurídica da UNIVALI, Itajaí, v.14, n.1, $1^{\circ}$ quadrimestre de 2019. Disponível em: www.univali.br/direitoepolitica - ISSN 1980-7791

\subsection{A Democracia E Proteção Dos Processos Ecológicos Essenciais: Em Busca Da Efetivação Dos Direitos Humanos Socioambientais}

A garantia dos processos ecológicos essenciais ou, por assim dizer, dos serviços ecossistêmicos, já vem sendo discutida no meio científico há muito tempo. Contudo, os limites ao atual modelo dito de desenvolvimento da sociedade globalizada trouxeram este debate para a ordem do dia.

Segundo a Avaliação Ecossistêmica do Milênio (AEM), estudo realizado a pedido da Organização das Nações Unidas (ONU) entre 2001 e 2005 envolvendo mais de 1.360 especialistas de 95 países, cerca de 60\% (15 entre 24) dos serviços dos ecossistemas examinados (incluindo $70 \%$ dos serviços reguladores e culturais) vem sendo degradados ou utilizados de forma não sustentável. A AEM resultou de solicitações governamentais por informações provenientes de quatro convenções internacionais - Convenção sobre Diversidade Biológica, Convenção das Nações Unidas de Combate à Desertificação, Convenção Ramsar sobre Zonas Úmidas e Convenção sobre Espécies Migratórias, visando suprir também as necessidades de outros grupos de interesse, incluindo comunidade empresarial, setor de saúde, organizações não governamentais e povos nativos.

Caso se mantenha o atual ritmo de crescimento, a humanidade precisará de pelo menos dois outros planetas Terra no final do século XXI para manter os padrões correntes de consumo. Para atenuar e reverter esses inúmeros problemas, esperava-se que na Conferência Rio+20 os líderes globais definissem um caminho para a transição rápida e justa ao desenvolvimento sustentável, que assegurasse um padrão de vida razoável para a população mundial e interrompesse a destruição dos ecossistemas.

Muito se tem discutido a respeito das mudanças globais, mais especialmente das mudanças climáticas, sobretudo após as divulgaçoes dos relatórios do IPCC, desde a década de 1990. O que não se tem discutido em profundidade, e mais uma vez o processo decorrente da Conferência Rio+20 poderia ter sido uma oportunidade,

crescimento adotado vitimizava igualmente outros grupos fragilizados étnica, social, cultural e politicamente. 
STANZIOLA VIEIRA, Ricardo; GOULART TAVARES, Elisa. Direito da sustentabilidade: reflexões acerca da crise ecológica marcada pela flexibilização das normas ambientais e a efetivação dos direitos humanos socioambientais. Revista Eletrônica Direito e Política, Programa de Pós-Graduação Stricto Sensu em Ciência Jurídica da UNIVALI, Itajaí, v.14, n.1, $1^{\circ}$ quadrimestre de 2019. Disponível em: www.univali.br/direitoepolitica - ISSN 1980-7791

são as relações destas mudanças climáticas (e seus termos de referência: mitigação, adaptação e resiliência) com a populações afetadas.

Estas últimas muitas vezes estão em condições de absoluta fragilidade/vulnerabilidade e acabam, sem ironia ou coincidência, sendo "vítimas preferenciais" das mudanças globais. Trata-se de uma nova espécie (muito indireta) de injustiça ambiental, ou já dito na introdução de injustiça climática. Neste sentido, propomos aqui a debater temas como desastres ecológicos e suas implicações para os Direitos Humanos e as políticas públicas.

Daí, decorre justamente a ideia de defesa do princípio de não retrocesso em matéria socioambiental. Este princípio vem da pauta de direitos humanos e terá grande repercussão na pauta do debate jurídico ambiental no nosso país. Da mesma forma que não aceitamos retrocesso das garantias individuais, também não há que se falar em retrocesso nas garantias coletivas e difusas.

O "Guia operacional sobre direitos humanos e desastres naturais", elaborado pelo Inter-Agency Standing Committee (IASC) ${ }^{26}$, ressalta a utilização do termo "naturais" por ser mais simples, sem desconsiderar que a magnitude das consequências de um desastre natural é determinada pela ação humana ou falta dela. Nesse documento, assim como no Manual que o acompanha, designado "Direitos Humanos e desastres naturais: linhas diretrizes operacionais e manual sobre o respeito aos Direitos Humanos em situações de desastres naturais", os desastres naturais são entendidos como consequências de eventos decorrentes de perigos naturais que ultrapassam a capacidade local de resposta e afetam seriamente o desenvolvimento econômico e social de uma região, gerando perdas humanas, materiais, econômicas e/ou ambientais e excedendo a habilidade dos afetados de fazer frente a elas por seus próprios meios.

26 IASC é um fórum de interagências único, de coordenação, desenvolvimento de políticas e processos decisórios, envolvendo parceiros humanitários tanto do sistema das Nações Unidas quanto externos. Foi criado em 1992, em consequência da Resolução 46/182, da Assembleia Geral das Nações Unidas, sobre o fortalecimento da assistência humanitária e, seu papel como primeiro mecanismo de cooperação interagências para a assistência humanitária foi afirmado pela Resolução 48/57, da Assembleia Geral das Nações Unidas. 
STANZIOLA VIEIRA, Ricardo; GOULART TAVARES, Elisa. Direito da sustentabilidade: reflexões acerca da crise ecológica marcada pela flexibilização das normas ambientais e a efetivação dos direitos humanos socioambientais. Revista Eletrônica Direito e Política, Programa de Pós-Graduação Stricto Sensu em Ciência Jurídica da UNIVALI, Itajaí, v.14, n.1, $1^{\circ}$ quadrimestre de 2019. Disponível em: www.univali.br/direitoepolitica - ISSN 1980-7791

A maior dificuldade em acessar determinadas informações e mesmo de mobilidade, a necessidade de ocupar áreas de risco e de grande fragilidade ambiental, ou mesmo de superexplorar os recursos naturais de seu ambiente para garantir a sobrevivência, fazem dos mais pobres as vítimas preferenciais dos desastres. Essa relação entre pobreza, degradação ambiental e desastres é bem explicitada pelo PNUMA $^{27}$ :

[...] os pobres são os mais vulneráveis aos desastres porque eles são frequentemente forçados a se estabelecer nas áreas marginais e têm menos acesso à prevenção, preparo e pronta advertência. Além disso, os pobres são os menos resilientes na recuperação dos desastres porque eles não dispõem de redes de suporte, seguros e opções alternativas de subsistência. ${ }^{28}$

Ainda que o desenvolvimento tecnológico de certa forma solucionou determinados problemas ambientais, em contrapartida, há um lado obscuro dessa realidade que é justamente a concentração em algumas partes do mundo, sob o controle de grandes corporações, que impede o acesso de seus produtos e serviços naturais para todos os seres humanos.

Em outras palavras, fala-se em tecnologia seleta ou privilegiada, ou seja, a tecnologia criou grupos com vantagens de acesso a estes serviços "muitas vezes substituídos dos naturais (sic) por nós. O irônico é que a destruição dos produtos e serviços naturais, em geral, se deve aos padrões de consumo desse mesmo grupo de privilegiados que terá acesso aos resultados do desenvolvimento tecnológico." 29 Portanto, evidente a exclusão social, uma vez que a degradação

\footnotetext{
27 De outro lado, o PNUMA reforça a relação entre desastres ecológicos e degradação ambiental, demonstrando que áreas degradas estão mais expostas ao risco de desastres. Em consequência, os indivíduos e as comunidades que ocupam áreas degradadas são, por sua vez, mais vulneráveis aos desastres ecológicos. Também a Declaração de Hyogo (Conferência Mundial sobre Redução de Desastres, 2005), adotada durante a Conferência Mundial para a Redução de Desastres, enfatiza as relações entre pobreza, vulnerabilidade ambiental e desastres.

28 PNUMA. Op cit., p. 25.

${ }^{29}$ Cf. BENSUSAN, Nurit. O que a natureza faz por nós : serviços ambientais. In : BENSUSAN, Nurit. (org.). Seria melhor mandar ladrilhar? Biodiversidade : como, para que e por quê. 2. Ed. São paulo : Peirópolis; Brasília : Editoria Universidade de Brasília, 2008. p. 255.
} 
STANZIOLA VIEIRA, Ricardo; GOULART TAVARES, Elisa. Direito da sustentabilidade: reflexões acerca da crise ecológica marcada pela flexibilização das normas ambientais e a efetivação dos direitos humanos socioambientais. Revista Eletrônica Direito e Política, Programa de Pós-Graduação Stricto Sensu em Ciência Jurídica da UNIVALI, Itajaí, v.14, n.1, $1^{\circ}$ quadrimestre de 2019. Disponível em: www.univali.br/direitoepolitica - ISSN 1980-7791

do meio ambiente agrava, drasticamente, os processos que geram injustiças sociais.

Num cenário de crise ecológica, recorrer a democracia com movimentos que demonstram a possibilidade se levar o desenvolvimento tecnológica para uma perspectiva mais justa, como uma oportunidade de globalizar diversas formas de coexistências, é adequando o sistema democrático às demandas de sustentabilidade e autocontenção oriundas do iminente colapso ambiental como forma de propiciar o debate acerca do surgimento de uma democracia deliberativa no âmbito ambiental ${ }^{30}$.

Nesse viés, entende-se que a democracia não apresenta apenas um aspecto procedimental (formal) todavia, apresenta também um aspecto material (substancial) referido às classes de direitos (em especial, os direitos fundamentais) ${ }^{31}$. São as normas formais da democracia política que definem quem decide e como ser decide (a maioria e por maioria), ao passo que as normas da democracia substancial estabelecem os temas sobre os que se pode e principalmente sobre os que não se pode decidir.

A ideia não é abrir mão do liberalismo, como podem sugerir alguns autores, mas, quando se fala em democracia deliberativa o principal ponto é a retomada de uma de uma racionalidade normativa, "fornecendo uma base sólida à democracia liberal ao conciliar a soberania democrática com a defesa das instituições liberais".

\footnotetext{
30Para Boaventura de Sousa Santos a democracia deliberativa/participativa e a democracia representativa são interdependentes, sendo que a primeira cria instâncias para a delegação da segunda, organizando-as a partir de espaços deliberativos tais como conselhos, audiências públicas, orçamento participativo, etc.

SANTOS, Boaventura de Souza. Presupuestacion Participativa Hacia Una Democracia redistributiva. Traducción de Júlio Caballero. Ruralter, Coimbra, v. 1, n. 2, p. 107-156, 1998. p. 153.

${ }^{31}$ Ferrajoli faz a seguinte divisão em 4 dimensões: democracia liberal, assegurada pela garantia dos direitos de liberdade, a democracia social, assegurada pela garantia dos direitos sociais, a democracia civil, assegurada pelas garantias dos direitos civis, ou seja, daqueles atribuídos às pessoas com capacidade de fato civil, e a democracia política, assegurada pelas garantias predispostas aos direitos políticos (direitos instrumentais cujos titulares são os cidadãos). FERRAJOLI, Luigi. Los fundamentos de los derechos fundamentales. In: FERRAJOLI, Luigi. et al. Los fundamentos de los derechos fundamentales. Madrid: Trotta 2001, p. 287.
} 
STANZIOLA VIEIRA, Ricardo; GOULART TAVARES, Elisa. Direito da sustentabilidade: reflexões acerca da crise ecológica marcada pela flexibilização das normas ambientais e a efetivação dos direitos humanos socioambientais. Revista Eletrônica Direito e Política, Programa de Pós-Graduação Stricto Sensu em Ciência Jurídica da UNIVALI, Itajaí, v.14, n.1, $1^{\circ}$ quadrimestre de 2019. Disponível em: www.univali.br/direitoepolitica - ISSN 1980-7791

Este, portanto, é o objeto do "Direito da Sustentabilidade", mais amplo do que aquilo que se tem entendido como objeto do Direito Ambiental. Tem como meta a integração entre as questões ambiental stricto sensu, social, econômica, política e cultural na análise e no tratamento dos dilemas de sustentabilidade enfrentados pela sociedade contemporânea. Portanto, o socioambientalismo e a Justiça Ambiental, ao preconizarem uma maior interface entre o social e o ambiental e a consideração de variáveis mais amplas do que o conhecimento técnico e científico na abordagem da questão ambiental, podem se apresentar como suportes teóricos e práticos para o Direito da Sustentabilidade e a consequente proteção aos Direitos Humanos Socioambientais.

\section{CONSIDERAÇÕES FINAIS}

Submeter as decisões ao sufrágio popular, enquanto elemento humano do Estado e fonte da qual emane o poder político deste, ante aos problemas ambientais é atentar-se às questões sociais ainda não solucionadas e mal resolvidas, dando voz e ouvidos aos que zelam e buscam por uma sociedade livre, justa e solidária, afinal são eles os detentores da titularidade difusa dos bens ambientais que contemplam as gerações presente e futuras.

Todo o processo envolvido nas Conferências das Nações Unidas sobre Meio Ambiente e Desenvolvimento (e também outras envolvendo temas de interesse planetário como habitação e urbanismo, gênero, direitos sociais) tem levado a um repensar da essência do Direito Ambiental. A realização da Rio+20 constituiu, assim, como visto anteriormente, mais uma "janela de oportunidade" para se avançar no sentido do que se pode chamar didaticamente de Direito da Sustentabilidade, por sua vez incorporado pelas reivindicações e alertas trazidos pela movimento da justiça ambiental e mais especificamente, no Brasil, pelo chamado socioambientalismo. 
STANZIOLA VIEIRA, Ricardo; GOULART TAVARES, Elisa. Direito da sustentabilidade: reflexões acerca da crise ecológica marcada pela flexibilização das normas ambientais e a efetivação dos direitos humanos socioambientais. Revista Eletrônica Direito e Política, Programa de Pós-Graduação Stricto Sensu em Ciência Jurídica da UNIVALI, Itajaí, v.14, n.1, $1^{\circ}$ quadrimestre de 2019. Disponível em: www.univali.br/direitoepolitica - ISSN 1980-7791

Para que o Direito Ambiental possa cumprir esta função, faz-se necessária uma ampliação do seu escopo para uma perspectiva socioambiental. É nesta direção que tem se desenvolvido e consolidado, no caso brasileiro, especialmente a partir da Constituição da República Federativa do Brasil de $1988^{32}$, um novo paradigma para o entendimento e a análise das inter-relações entre ambiente e sociedade, sugerindo até mesmo que o modelo de Estado no Brasil possa ser denominado, por alguns autores como "Estado Ambiental de Direito"33.

Um dos aspectos mais inovadores deste debate é a renovação do conjunto do Direito Ambiental, aqui entendido em suas dimensões internacionais, comunitárias e estatais, sendo que esse Direito, por sua vez, representa um grande fator de renovação do Direito como um todo. Sobre esta "tendência" inovadora do Direito e do Direito Ambiental mais especificamente, têm se dedicado pensadores, como Gérard Monediaire, François Ost, Mireille Delmas Marty, Charles Albert Morin, entre outros.

Este novo "Direito do Desenvolvimento Sustentável", mais versátil e flexível, seria a forma mais adequada para dar conta da complexidade e das grandes transformações que assolam o mundo contemporâneo. O alcance da sustentabilidade ultrapassa a mera preservação e conservação de bens ambientais e a análise técnico-jurídica dos dilemas ambientais da humanidade. Requer a promoção da qualidade de vida em toda a sua amplitude, que inclui geração de emprego e renda; desenvolvimento humano e econômico equitativo; acesso à educação e, em especial, à informação; possibilidade de exercício da cidadania e democratização dos processos decisórios; promoção do multiculturalismo; superação da desigualdade; exclusão social e ambiental; bem como o respeito a todas as etnias.

\footnotetext{
32 Marés aponta a natureza essencialmente coletiva dos direitos constitucionais reconhecidos aos povos indígenas, aos quilombolas e às outras populações tradicionais, e a quebra do paradigma constitucional individualista, reafirmando a "quase impossibilidade" de sobrevivência do multiculturalismo em um mundo no qual o Estado reconheça apenas os direitos individuais. Cf. SOUZA FILHO, Carlos Frederico Marés de. Multiculturalismo e Direitos Coletivos. In: SANTOS, Boaventura de Sousa (Org.). Reconhecer para libertar: os caminhos do cosmopolitismo cultural. Rio de Janeiro: Civilização Brasileira, 2003, p. 93 e ss.

${ }^{33}$ Cf. LEITE, José Rubens Morato; AYALA, Patryck de Araújo. Direito Ambiental na sociedade de risco. Rio de Janeiro: Forense Universitária, 2002.
} 
STANZIOLA VIEIRA, Ricardo; GOULART TAVARES, Elisa. Direito da sustentabilidade: reflexões acerca da crise ecológica marcada pela flexibilização das normas ambientais e a efetivação dos direitos humanos socioambientais. Revista Eletrônica Direito e Política, Programa de Pós-Graduação Stricto Sensu em Ciência Jurídica da UNIVALI, Itajaí, v.14, n.1, $1^{\circ}$ quadrimestre de 2019. Disponível em: www.univali.br/direitoepolitica - ISSN 1980-7791

\section{REFERÊNCIAS DAS FONTES CITADAS}

ACSELRAD, Henri; HERCULANO, Selene; PÁDUA, José Augusto. A justiça ambiental e a dinâmica das lutas socioambientais no Brasil - uma introdução. In: Justiça Ambiental e Cidadania. Rio de Janeiro: Relume Dumará; Fundação Ford, 2004.

ALEDO, Antonio Tur; DOMINGUEZ, J. Andrés. Presentación de la obra: La sociologia ante la crisis ambienta. In: GóMEZ, José nAndés Dominguéz (Directores). Sociologia Ambiental. Grupo Editorial Universitário, 2001.

ALONSO, Ângela; COSTA, Valeriano. Por uma sociologia dos conflitos ambientais no Brasil. In: ALIMONDA, Héctor (Org.). Ecología Política. Naturaleza, Sociedad y Utopia. Buenos Aires: CLACSO, 2002.

ANTYPAS, A. et. al. Linking environmental protection, health, and human rights in the European Union: an argument in favour of environmental justice policy. New York: Environmental Law \& Management, 2008.

BENSUSAN, Nurit. O que a natureza faz por nós: serviços ambientais. In : BENSUSAN, Nurit. (org.). Seria melhor mandar ladrilhar? Biodiversidade : como, para que e por quê. 2. Ed. São paulo: Peirópolis; Brasília : Editoria Universidade de Brasília, 2008.

BROWN, Lester. Plano B 4.0 Mobilização para salvar a civilização. São Paulo: New Content Editora e Produtora, 2009.

BRUM, Eliane. Perdão, Aaron Schwartz- A morte de um gênio da internet, aos 26 anos, é um marco trágico do nosso tempo. É hora de pensar sobre nossas ações - ou omissões. In Revista Época, de 21 de janeiro de 2013. Disponível em: <http://revistaepoca.globo.com/Sociedade/eliane-brum/noticia/2013/01/perdaoaaron-swartz.html>.

CIDCE/CRIDEAU. Projeto de Convenção sobre o Estatuto Internacional dos Deslocados Ambientais. In Revue Européenne du Droit de L'Environnement. n. 4, p. 381-393. Paris : Presses universitaires de Limoges, 2008. 
STANZIOLA VIEIRA, Ricardo; GOULART TAVARES, Elisa. Direito da sustentabilidade: reflexões acerca da crise ecológica marcada pela flexibilização das normas ambientais e a efetivação dos direitos humanos socioambientais. Revista Eletrônica Direito e Política, Programa de Pós-Graduação Stricto Sensu em Ciência Jurídica da UNIVALI, Itajaí, v.14, n.1, $1^{\circ}$ quadrimestre de 2019. Disponível em: www.univali.br/direitoepolitica - ISSN 1980-7791

COMISSÃO PARA OS DIREITOS HUMANOS DA ONU. Direitos humanos e meio ambiente como parte do desenvolvimento sustentável. UNDoc/ACNUDH/Res $2003 / 71$.

CONSELHO DE DIREITOS HUMANOS DA ONU. Resolução 7/23 Direitos Humanos e Mudanças Climáticas.

DELMAS-MARTY, Mireille. Le Pluralisme Ordonné - Les forces imaginantes du droit (II). Paris: Seuil, 2006.

DOBSON, Andrew. Justice and the environment - conceptions of environmental sustainability and dimensions of social justice. Oxford: Oxford University Press, 1998.

FERRAJOLI, Luigi. Los fundamentos de los derechos fundamentales. In: FERRAJOLI, Luigi. et al. Los fundamentos de los derechos fundamentales. Madrid: Trotta 2001.

GARCÍA, E.; RODRIGUÉZ, J. M. La expansión de la civilización industrial y sus limites. In: GARCÍA, Ferrando Manuel. (Coord.). Pensar nuestra sociedade global: fundamentos de Sociologia. Valencia: Tirant lo Blanch, 2005. P. 265-299.

GOULD, Kenneth. A. Clase social, justice ambiental e conflito político. In: ACSELRAD, Henri; HERCULANO, Selene; PÁDUA, José Augusto. Justiça Ambiental e Cidadania. Rio de Janeiro: Relume Dumará; Fundação Ford, 2004.

HARVEY, David. Espacios de esperanza. Madrid: Akal, 2003.

LATOUCHE, Serge. Pensar diferentemente. Por uma ecologia da civilização planetária. In Ecodebate - Cidadania e Meio Ambiente. Disponível em: <http://goo.gl/pUm7vJ>.

LEFF, Henrique. Racionalidade Ambiental a Reapropriação Social da Natureza. São Paulo: Civilizacao Brasileira, 2006 
STANZIOLA VIEIRA, Ricardo; GOULART TAVARES, Elisa. Direito da sustentabilidade: reflexões acerca da crise ecológica marcada pela flexibilização das normas ambientais e a efetivação dos direitos humanos socioambientais. Revista Eletrônica Direito e Política, Programa de Pós-Graduação Stricto Sensu em Ciência Jurídica da UNIVALI, Itajaí, v.14, n.1, $1^{\circ}$ quadrimestre de 2019. Disponível em: www.univali.br/direitoepolitica - ISSN 1980-7791

LEITE, José Rubens Morato; AYALA, Patryck de Araújo. Direito Ambiental na sociedade de risco. Rio de Janeiro: Forense Universitária, 2002.

LIENHARD, C. Pour un droit des catastrophes. Paris: Recueil Le Dalloz, 1995.

MARÉS, Carlos Frederico. Introdução ao Direito Socioambiental. In LIMA, André (Org.). O Direito para o Brasil Socioambiental. Porto Alegre: Sérgio Antônio Fabris Editor, 2002.

MARÉS, Carlos Frederico. Multiculturalismo e Direitos Coletivos. In: SOUSA SANTOS, Boaventura de (Org.). Reconhecer para libertar: os caminhos do cosmopolitismo cultural. Rio de Janeiro: Civilização Brasileira, 2003.

MIRRA, Álvaro Luiz Valery. Ação Civil Pública e a reparação do dano ao meio ambiente. São Paulo: Juarez de Oliveira, 2002.

MONEDIAIRE, Gérard. L'hypothèse d'un droit du développement durable. In: MATAGNE, Patrick. Les Enjeux du Développment Durable. Paris: L' Harmattan, 2005.

MORAND, Charles-Albert. Le droit néo-moderne des politiques publiques. Paris: Librairie Générale de Droit et de Jurisprudence, 1999. Coleção Droit et Société.

----- Le Droit Saisi par la mondialisation. Bruxeles: Bruyant, 2001.

\begin{tabular}{lrrlrcr} 
ORGANIZAÇÃO & & DAS & NAÇÕES & \multicolumn{2}{c}{ UNIDAS } & (ONU). \\
Declaração & do & Rio & sobre & Meio & Ambiente & e \\
Desenvolvimento & & adotada & em & 1992. & Disponível & em:
\end{tabular}

<http://www.onu.org.br/rio20/img/2012/01/rio92.pdf>

Acesso em: 06. ago. 2017

ONU. ORGANIZAÇÃO DAS NAÇÕES UNIDAS. Protocolo de Nagóia no âmbito da Convenção da Diversidade Biológica Sobre acesso a Recursos Genéticos e a Repartição Justa e Equitativa dos Benefícios decorrentes de sua utilização, 2010. Disponível em: < 
STANZIOLA VIEIRA, Ricardo; GOULART TAVARES, Elisa. Direito da sustentabilidade: reflexões acerca da crise ecológica marcada pela flexibilização das normas ambientais e a efetivação dos direitos humanos socioambientais. Revista Eletrônica Direito e Política, Programa de Pós-Graduação Stricto Sensu em Ciência Jurídica da UNIVALI, Itajaí, v.14, n.1, $1^{\circ}$ quadrimestre de 2019. Disponível em: www.univali.br/direitoepolitica - ISSN 1980-7791

http://portal.iphan.gov.br/uploads/ckfinder/arquivos/Protocol

o_de_nagoia.pdf> Acesso: em 01. Fev. 2017

OST, François. Júpiter, Hercule, Hermes: trois modele du juge. In BOURETZ, Pierre. La force du droit - Panorama des débats contemporains. France: Éditions Esprit, 1991.

PNUMA, 2011. Caminhos para o Desenvolvimento Sustentável e a Erradicação da Pobreza - Síntese para Tomadores de Decisão. Disponível em: $<$ www.unep.org/greeneconomy $>$.

PORTO, Marcelo Firpo; ALIER, Joan Martinez. Ecologia política, economia ecológica e saúde coletiva: interfaces para a sustentabilidade do desenvolvimento e para a promoção da saúde. In Caderno Saúde Pública. v. 23. Rio de Janeiro: Escola Nacional de Saúde Pública Sergio Arouca, Fundação Oswaldo Cruz, 2007.

PETRELLA, Ricardo. Désir D'Humanité - Le Droit de rêver. Bruxelles: Editions Labor, 2004.

SACHS, Ignacy. Qual desenvolvimento para o século XXI? In Barrère M. Terra, patrimônio comum: A ciência a serviço do meio ambiente e do desenvolvimento. São Paulo: Nobel, 1992.

SANTILLI, Juliana. Socioambientalismo e novos direitos - proteção jurídica à diversidade biológica e cultural. São Paulo: Peirópolis, 2004.

SICHES, Recasens. Nueva filosofia de la interpretacion del derecho. México: Porrúa, 1973.

RECIBIDO EM: 14/11/2018

APROVADO EM: 20/02/2019 